\title{
Changes of adrenomedullin and natriuretic peptides in patients with adrenal medullary hyperplasia prior to and following pharmacological therapy and adrenalectomy
}

\author{
PANG-HU ZHOU ${ }^{1 *}$, LEI SHI ${ }^{2 *}$, WEI HU ${ }^{3}$, XIAO-BIN ZHANG ${ }^{3}$, WEI WANG ${ }^{3}$ and LI-JUN ZHANG ${ }^{3}$ \\ Departments of ${ }^{1}$ Orthopedics, ${ }^{2}$ Oncology and ${ }^{3}$ Urology, Renmin Hospital of Wuhan University, \\ Wuhan, Hubei 430060, P.R. China
}

Received April 9, 2015; Accepted May 16, 2016

DOI: $10.3892 / \mathrm{etm} .2016 .3418$

\begin{abstract}
The aim of the present study was to investigate the pathophysiological functions of adrenomedullin (ADM), atrial and brain natriuretic peptides (ANP and BNP) in patients with adrenal medullary hyperplasia (AMH). Plasma ADM, ANP and BNP concentrations were measured in 20 patients with $\mathrm{AMH}$, 35 patients with essential hypertension $(\mathrm{EH})$, and 40 healthy control subjects. Following effective antihypertensive therapy, the values in $\mathrm{AMH}$ and $\mathrm{EH}$ patients were measured again and laparoscopic adrenalectomy was performed for $\mathrm{AMH}$ patients. At 2 weeks after surgery, the three peptides were measured again. The AMH patients had higher plasma concentrations of ADM, ANP and BNP compared with the EH and control subjects. There were significant differences in the values of ADM, ANP and BNP between adrenal vein and inferior vena cava and between $\mathrm{AMH}$ and contralateral adrenal vein. Plasma ADM concentration was correlated with serum epinephrine and norepinephrine and urine vanillylmandelic acid, in addition to systolic and diastolic blood pressure, left ventricular ejection fraction, left ventricular mass index and ANP and BNP values in the AMH group. Following antihypertensive treatment, ADM, ANP and BNP were significantly decreased in $\mathrm{EH}$ patients, but remained unchanged in $\mathrm{AMH}$ subjects. However, these concentrations significantly decreased following surgery. Therefore, the present results suggest that ADM, ANP and BNP may be involved in regulating adrenal medulla functions.
\end{abstract}

Correspondence to: Dr Wei Hu, Department of Urology, Renmin Hospital of Wuhan University, 238 Liberation Road, Wuhan, Hubei 430060, P.R. China

E-mail: huwei_abc970642@163.com

*Contributed equally

Key words: adrenomedullin, atrial natriuretic peptide, brain natriuretic peptide, adrenal medullary hyperplasia

\section{Introduction}

Adrenomedullin (ADM) was originally isolated from human pheochromocytoma as a biologically active peptide with potent vasodilating action (1). Human ADM consists of 52 amino acids and has a ring structure, with one intramolecular disulfide bond and an amidated carboxyl terminal, similar to calcitonin gene-related peptide and amylin (2). At present, it has been demonstrated that ADM and its receptors are expressed in several tissues, including the heart and blood vessels, kidneys, lungs, atrium, gastrointestinal tract, spleen and thymus, endocrine glands and brain (3). The synthesis of ADM can be influenced by physical factors, including shear stress, ventricular wall stress and hypoxia and humoral factors such as cytokines, endocrine and paracrine hormones (4). Following its release from diverse tissues, ADM functions as an autocrine or a paracrine hormone to regulate vascular tone and blood pressure (5). ADM exerts its biological functions directly via cyclic adenosine 3,5-monophosphate and indirectly via endothelial nitric oxide $(6,7)$. The natriuretic peptide system, including atrial and brain natriuretic peptides (ANP and BNP), causes natriuresis, diuresis and plasma shift to increase oxygen transport in healthy humans to counteract hypoxic conditions and the stimulus to which the synthesis and release of natriuretic peptides responds is the oxygen gradient among cardiocytes $(8,9)$. Studies using cultured cardiomyocytes (particularly from rodents) have demonstrated that several factors, including calcium, catecholamines, endothelins, angiotensin II and certain cytokines, are able to regulate the expression of ANP and BNP genes (10). Numerous cardiovascular diseases, such as chronic heart failure, systemic hypertension, coronary disease, endothelial dysfunction and others are responsible for their increased secretion (11). ANP and BNP, predominantly synthesized and released by atrial and ventricular myocytes, respectively, exert their biological actions via an accumulation of intracellular cyclic GMP (cGMP) (12), whereas many of the actions of ADM are mediated by cAMP (13). It has been reported that plasma ADM concentration was higher in pheochromocytoma patients compared with healthy subjects, and catecholamines are able to regulate the expression of ANP and BNP genes $(10,14)$. Therefore, we hypothesized that ADM, ANP and BNP may 
be involved in the regulation of adrenal medulla functions in adrenal medullary hyperplasia (AMH) patients.

To assess possible changes in plasma concentrations of ADM, ANP and BNP and investigate their pathophysiological roles in $\mathrm{AMH}$ patients, we measured the three peptides in untreated $\mathrm{AMH}$ patients, EH patients and healthy control subjects. The concentrations of ADM and catecholamines in the plasma from the adrenal vein and the inferior vena cava (IVC) of AMH patients were measured. In addition, we measured ADM, ANP and BNP levels after 4 weeks of effective antihypertensive therapy for $\mathrm{EH}$ and $\mathrm{AMH}$ patients. Then laparoscopic adrenalectomy for $\mathrm{AMH}$ patients was performed and the values of the three peptides were measured again 2 weeks later. Then we compared the results before and after treatment.

\section{Subjects and methods}

Study subjects. Between January 2006 and October 2014, $20 \mathrm{AMH}$ patients (mean age, $43.0 \pm 5.5$ years; age range, 34-52 years), $35 \mathrm{EH}$ patients (mean age, 43.2 \pm 5.7 years; age range, 33-55 years) and 40 healthy control subjects (mean age, $42.0 \pm 4.9$ years; age range, 32-52 years) were recruited from Renmin Hospital of Wuhan University (Wuhan, China). All subjects agreed with the aim and provided informed consent to participate in the present study.

Diagnostic tests. Routine laboratory and radiological studies of all patients included assays of blood routine test; urinalysis; serum electrolytes and fasting blood glucose level; liver and kidney function tests; serum renin activity, aldosterone, catecholamines, cortisol, and thyroid hormones; 24-h urine vanillylmandelic acid; a chest roentgenogram; an electrocardiogram; B-scan ultrasonography of liver, cholecyst, pancreas, spleen, kidneys and adrenal glands. Other radiological studies included one or more of the following diagnostic methods: Magnetic resonance imaging, computed tomography, positron emission tomography (PET) imaging with fluorodeoxyglucose, dihydroxyphenylalanine-PET-computed tomography, octreotide scan and ${ }^{123}$ I-metaiodo-benzylguanidine scintigraphy. Furthermore, blood samples from adrenal veins were collected in all AMH patients who clearly showed excessive secretion of catecholamines under fluoroscopic control. The blood was also collected for preparing the plasma samples for the measurement of both ADM and catecholamines. Serum catecholamines were measured by highly sensitive and specific high-performance liquid chromatography methods using electrochemical detection (LC-10Avp Plus; Shimadzu Co., Ltd., Kyoto, Japan).

Diagnosis of AMH. AMH patients with a familial history of MEN syndrome were excluded from the study. Imaging examinations did not show any abnormal masses suggestive of pheochromocytoma or other tumors which are indicative of MEN-2. AMH, due to twelve cases of left and eight cases of right increased adrenomedullary tissue, was diagnosed on the basis of certain clinical manifestations and imaging examinations mentioned above, in addition to adrenal venous blood sample analysis. The clinical manifestations include dizziness, flushing, tremor, diaphoresis, headache, palpitations, sweating, anxiety, a medical history of hypertension and excessive catecholamine excretion. However, it was further confirmed by the postoperative histopathological results of the extirpated lesions at surgery, which showed histomorphometric evidence of increased adrenomedullary tissue relative to the cortex in the absence of MEN and proliferation of cells containing normal cellular architecture as opposed to the nests of cytologically atypical polygonal cells that characterize pheochromocytoma. Gene detection showed no identifiable mutation in the RET proto-oncogene. All AMH patients were hypertensive according to WHO criteria (15) (systolic pressure, $\geq 140 \mathrm{mmHg}$; and/or diastolic pressure, $\geq 90 \mathrm{mmHg}$ ). None of these patients exhibited clinical evidence of cardiac or hepatic failure, diabetes, pulmonary disease, angina pectoris, myocardial infarction, Cushing's syndrome, primary aldosteronism or other diseases that can result in secondary hypertension. All AMH patients had no previous antihypertensive drug treatment or who had not received any antihypertensive therapy in the prior 4 weeks. Furthermore, the medications they used made no difference to serum concentrations of catecholamines. Healthy controls were age- and sex-matched normotensive subjects that had been hospitalized for a healthy checkup.

Treatment. After the initial evaluation, $20 \mathrm{AMH}$ patients were started on antihypertensive therapy with phenoxybenzamine (Topfond Pharmaceutical Co., Ltd., Zhengzhou, China) at $10 \mathrm{mg}$ once or twice daily and increased by $10-20 \mathrm{mg}$ every 2-3 days for optimal blood pressure and symptom control to be normal. Furthermore, $35 \mathrm{EH}$ patients received antihypertensive therapy with slow-release nifedipine (Bayer AG, Leverkusen, Germany) at 10-30 mg twice daily for optimal blood pressure control to be normal. Plasma concentrations of ADM, ANP and BNP were determined prior to the initiation of therapy and after 4 weeks of effective antihypertensive treatment. After the conditions of all AMH patients were optimized prior to surgery, unilateral laparoscopic adrenalectomy was performed in all AMH cases. Adrenalectomy was performed by a transperitoneal laparoscopic approach in all 20 cases. After 2 weeks, the therapeutic effect was evaluated with normalization of catecholamine hypersecretion and complete disappearance of symptoms, as well as the reduction or abstention of antihypertensive therapy. The values of ADM, ANP and BNP were measured for a third time.

Preparations of human ADM, ANP and BNP. Blood samples were drawn from an antecubital vein between 7:00 and 8:00 (morning) after an overnight fast and a supine rest, and were transferred to ice-chilled tubes with $1 \mathrm{mg} / \mathrm{ml}$ EDTA-2Na and 500 kallikrein inhibitory units (KIU)/ml aprotinin (Amresco Co., Ltd., Solon, OH, USA). Plasma was obtained by centrifugation at $600 \mathrm{x}$ g for $10 \mathrm{~min}$ at $4^{\circ} \mathrm{C}$ and then immediately frozen and stored in polypropylene tubes at $-70^{\circ} \mathrm{C}$ until determination.

Hormone measurements. Plasma ADM concentrations were measured by immunoradiometric assay using a specific kit (Shionogi \& Co., Ltd., Osaka, Japan) after extraction and purification as described previously $(16,17)$. Briefly, $2 \mathrm{ml}$ plasma was applied to a Sep-Pak C18 cartridge (Waters Corporation, Milford, MA, USA) equilibrated with $5 \mathrm{ml}$ saline. After the cartridge was washed with $5 \mathrm{ml}$ isotonic saline and $10 \%$ 
Table I. Clinical characteristics of study subjects.

\begin{tabular}{lccc}
\hline Parameter & Control $(\mathrm{n}=40)$ & EH $(\mathrm{n}=35)$ & AMH $(\mathrm{n}=20)$ \\
\hline Age (years) & $42.0 \pm 4.9$ & $43.2 \pm 5.7$ & $43.0 \pm 5.5$ \\
Gender (male:female) & $23: 17$ & $20: 15$ & $11: 9$ \\
Systolic BP (mmHg) & $120 \pm 8$ & $162 \pm 12^{\mathrm{a}}$ & $168 \pm 15^{\mathrm{a}}$ \\
Diastolic BP (mmHg) & $80 \pm 6$ & $101 \pm 6^{\mathrm{a}}$ & $104 \pm 7^{\mathrm{a}}$ \\
BUN (mg/dl) & $17 \pm 3$ & $20 \pm 4^{\mathrm{a}}$ & $21 \pm 5^{\mathrm{a}}$ \\
Scr (mg/dl) & $1.0 \pm 0.2$ & $1.5 \pm 0.4^{\mathrm{a}}$ & $1.6 \pm 0.6^{\mathrm{a}}$ \\
GFR (ml/min) & $96 \pm 8$ & $90 \pm 12^{\mathrm{a}}$ & $85 \pm 14^{\mathrm{a}}$ \\
Serum E (pg/ml) & $56 \pm 15$ & $63 \pm 18$ & $211 \pm 98^{\mathrm{a}, \mathrm{b}}$ \\
Serum NE (pg/ml) & $221 \pm 67$ & $233 \pm 75$ & $738 \pm 292^{\mathrm{a}, \mathrm{b}}$ \\
Urine VMA (mg/24 h) & $4 \pm 1$ & $5 \pm 2$ & $16 \pm 9^{\mathrm{a}, \mathrm{b}}$ \\
LVEF $(\%)$ & $83 \pm 5$ & $79 \pm 6^{\mathrm{a}}$ & $75 \pm 7^{\mathrm{a}, \mathrm{b}}$ \\
LVMI $\left(\mathrm{g} / \mathrm{m}^{2}\right)$ & $115 \pm 7$ & $128 \pm 10^{\mathrm{a}}$ & $140 \pm 15^{\mathrm{a}, \mathrm{b}}$ \\
\hline
\end{tabular}

EH, essential hypertension; AMH, adrenal medullary hyperplasia; BP, blood pressure; BUN, blood urea nitrogen; Scr, serum creatinine; GFR, glomerular filtration rate; E, epinephrine; NE, norepinephrine; VMA, vanillylmandelic acid; LVEF, left ventricular ejection fraction; LVMI, left ventricular mass index. The normal values for catecholamines are as follows: serum epinephrine, 0 to $100 \mathrm{pg} / \mathrm{ml}$; serum norepinephrine, 0 to $600 \mathrm{pg} / \mathrm{ml}$; urine vanillylmandelic acid, 1 to $6 \mathrm{mg} / 24 \mathrm{~h}$. ${ }^{\mathrm{a}} \mathrm{P}<0.05 \mathrm{vs}$. control subjects; ${ }^{\mathrm{b}} \mathrm{P}<0.05 \mathrm{vs}$. EH patients.

acetonitrile in $0.1 \%$ trifluoroacetic acid (TFA), the absorbed materials were eluted with $4 \mathrm{ml} 60 \%$ acetonitrile in $0.1 \%$ TFA, lyophilized, and stored at $-70^{\circ} \mathrm{C}$ until determination. The residue was dissolved in $300 \mu \mathrm{l}$ radioimmunoprecipitation assay (RIA) buffer (Phoenix Pharmaceuticals, Inc., Belmont, CA, USA), $50 \mathrm{mmol} / 1$ sodium phosphate buffer (pH 7.4) containing $0.5 \%$ bovine serum albumin (Santa Cruz Biotechnology, Inc., Santa Cruz, CA, USA), 0.5\% Triton $\mathrm{X}-100,80 \mathrm{mmol} / 1$ sodium chloride, $25 \mathrm{mmol} / 1 \mathrm{EDTA}$, $0.05 \%$ sodium azide and $500 \mathrm{KIU} / \mathrm{ml}$ aprotinin. Next, $100 \mu \mathrm{l}$ dissolved plasma extract was subjected to a specific RIA for human ADM (hADM) as reported previously $(16,17)$. According to the manufacturer's instructions, the anti-hADM antibody (cat. no. RIN9500; Peninsula Laboratories, Belmont, CA, USA) used in this RIA had no any cross-reactivity with hAM- (13-52), rat ADM-(1-50), human CGRP, calcitonin, $\alpha$-human atrial natriuretic peptide-(1-28), brain natriuretic peptide-32, or C-type natriuretic peptide-22 and neuropeptide Y. The reproducibility of the RIA was estimated using three plasma samples having different ADM concentrations. All assays were performed three times and the mean of three measurements was used. The detection limit was $0.5 \mathrm{pmol} / 1$ and the working range $(\mathrm{CV},<15 \%)$ was $1-300 \mathrm{pmol} / \mathrm{l}$. The intra- and interassay imprecision values were 3.2-7.5 and 5.4-8.7\%, respectively. Concentrations of ADM are expressed as $\mathrm{pmol} / \mathrm{l}$.

The plasma ANP and BNP concentrations were measured with specific immunoradiometric assays for human ANP and BNP (Shionogi \& Co., Ltd.). The accuracies and the detailed methods of these assays have been described previously (18).

Statistical analysis. All continuous data were expressed as the mean \pm standard deviation, and analyzed using SPSS software, version 19.0 (SPSS, Inc., Chicago, IL, USA). Comparisons between two variables were performed with unpaired t-test. Multiple comparisons were evaluated with analysis of variance

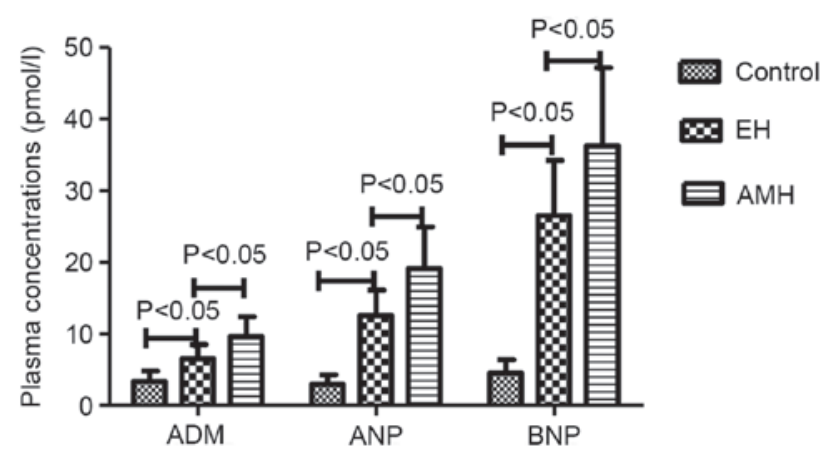

Figure 1. Plasma concentrations of ADM, ANP and BNP in control, EH and $\mathrm{AMH}$ groups. The mean concentrations of ADM, ANP and BNP were significantly higher in the AMH group compared with the $\mathrm{EH}$ and control groups $(\mathrm{P}<0.05)$. Significant differences in the mean concentrations of ADM, ANP and $\mathrm{BNP}$ were detected between the $\mathrm{EH}$ patients and controls $(\mathrm{P}<0.05) . \mathrm{EH}$, essential hypertension; AMH, adrenal medullary hyperplasia; ADM, adrenomedullin; ANP, atrial natriuretic peptide; BNP, brain natriuretic peptide.

followed by Student-Newman-Keuls' method. The significance of differences between paired variables was determined by paired t-test. Categorical variables were assessed using the $\chi^{2}$ or Fisher's exact tests. Stepwise multiple linear regression analysis was conducted to evaluate the most important factor for catecholamines or blood pressure. The correlation between two variables was performed using linear regression analysis and the significance was further confirmed using Spearman's rank test. Non-normal distribution data were performed by Mann-Whitney U test or Kruskal-Wallis method. $\mathrm{P}<0.05$ was considered to indicate a statistically significant difference.

\section{Results}

Clinical characteristics. Table I shows the clinical profiles of the study groups. There were no significant differences in age and sex distribution among the three groups. The mean values 
Table II. Concentrations of E, NE, ADM, ANP and BNP in the IVC and adrenal vein of twelve patients with left AMH.

\begin{tabular}{lccrc}
\hline Parameter & Infraadrenal IVC & Supraadrenal IVC & Right adrenal vein & Left adrenal vein \\
\hline E $(\mathrm{pg} / \mathrm{ml})$ & $382 \pm 106$ & $424 \pm 123$ & $564 \pm 157^{\mathrm{a}, \mathrm{b}}$ & $2,148 \pm 676^{\mathrm{a}-\mathrm{c}}$ \\
$\mathrm{NE}(\mathrm{pg} / \mathrm{ml})$ & $846 \pm 364$ & $1,014 \pm 392$ & $1,532 \pm 426^{\mathrm{a}, \mathrm{b}}$ & $5,752 \pm 1684^{\mathrm{a}-\mathrm{c}}$ \\
ADM $(\mathrm{pmol} / \mathrm{l})$ & $12.31 \pm 4.98$ & $14.72 \pm 5.83$ & $23.24 \pm 7.92^{\mathrm{a}, \mathrm{b}}$ & $34.56 \pm 10.64^{\mathrm{a}-\mathrm{c}}$ \\
ANP $(\mathrm{pmol} / \mathrm{l})$ & $18.74 \pm 6.43$ & $21.32 \pm 7.71$ & $30.96 \pm 9.97^{\mathrm{a}, \mathrm{b}}$ & $41.54 \pm 11.63^{\mathrm{a}-\mathrm{c}}$ \\
BNP $(\mathrm{pmol} / \mathrm{l})$ & $30.82 \pm 9.58$ & $34.37 \pm 10.72$ & $45.49 \pm 12.38^{\mathrm{a}, \mathrm{b}}$ & $58.29 \pm 14.48^{\mathrm{a}-\mathrm{c}}$ \\
\hline
\end{tabular}

E, epinephrine; NE, norepinephrine; ADM, adrenomedullin; ANP, atrial natriuretic peptide; BNP, brain natriuretic peptide; IVC, inferior vena cava; $\mathrm{AMH}$, adrenal medullary hyperplasia. ${ }^{\mathrm{a}} \mathrm{P}<0.05$ vs. infraadrenal IVC; ${ }^{\mathrm{b}} \mathrm{P}<0.05$ vs. supraadrenal IVC; ${ }^{\mathrm{c}} \mathrm{P}<0.05 \mathrm{vs}$. right adrenal vein.

Table III. Concentrations of E, NE, ADM, ANP and BNP in the IVC and adrenal vein of eight patients with right AMH.

\begin{tabular}{lcccc}
\hline Parameter & Infraadrenal IVC & Supraadrenal IVC & Left adrenal vein & Right adrenal vein \\
\hline E $(\mathrm{pg} / \mathrm{ml})$ & $391 \pm 102$ & $436 \pm 147$ & $643 \pm 156^{\mathrm{a}, \mathrm{b}}$ & $1,948 \pm 591^{\mathrm{a}-\mathrm{c}}$ \\
$\mathrm{NE}(\mathrm{pg} / \mathrm{ml})$ & $931 \pm 423$ & $1,053 \pm 498$ & $1,891 \pm 587^{\mathrm{a}, \mathrm{b}}$ & $5,468 \pm 1573^{\mathrm{a}-\mathrm{c}}$ \\
$\mathrm{ADM}(\mathrm{pmol} / \mathrm{l})$ & $11.28 \pm 5.47$ & $14.98 \pm 6.04$ & $25.13 \pm 8.56^{\mathrm{a}, \mathrm{b}}$ & $36.89 \pm 11.81^{\mathrm{a}-\mathrm{c}}$ \\
ANP $(\mathrm{pmol} / \mathrm{l})$ & $17.92 \pm 6.91$ & $20.81 \pm 8.56$ & $30.95 \pm 10.14^{\mathrm{a}, \mathrm{b}}$ & $44.13 \pm 12.84^{\mathrm{a}-\mathrm{c}}$ \\
BNP $(\mathrm{pmol} / \mathrm{l})$ & $29.58 \pm 9.12$ & $32.31 \pm 10.32$ & $44.82 \pm 11.71^{\mathrm{a}, \mathrm{b}}$ & $59.45 \pm 13.78^{\mathrm{a}-\mathrm{c}}$ \\
\hline
\end{tabular}

E, epinephrine; NE, norepinephrine; ADM, adrenomedullin; ANP, atrial natriuretic peptide; BNP, brain natriuretic peptide; IVC, inferior vena cava; AMH, adrenal medullary hyperplasia. ${ }^{a} \mathrm{P}<0.05$ vs. infraadrenal IVC; ${ }^{\mathrm{b}} \mathrm{P}<0.05$ vs. supraadrenal IVC; ${ }^{\mathrm{c}} \mathrm{P}<0.05 \mathrm{vs}$. left adrenal vein.

Table IV. Stepwise multiple regression analysis of significant factors for SBP, DBP, serum E, serum NE or urine VMA in AMH patients.

\begin{tabular}{|c|c|c|c|c|c|c|c|c|c|c|c|c|c|c|c|}
\hline \multirow[b]{2}{*}{ Variable } & \multicolumn{3}{|c|}{ SBP } & \multicolumn{3}{|c|}{ DBP } & \multicolumn{3}{|c|}{ Serum E } & \multicolumn{3}{|c|}{ Serum NE } & \multicolumn{3}{|c|}{ Urine VMA } \\
\hline & B & $\mathrm{t}$ & $\mathrm{P}$ & B & $\mathrm{t}$ & $\mathrm{P}$ & B & $\mathrm{t}$ & $\mathrm{P}$ & B & $\mathrm{t}$ & $\mathrm{P}$ & B & $\mathrm{t}$ & $\mathrm{P}$ \\
\hline ADM & 3.287 & 2.486 & 0.024 & 1.638 & 2.255 & 0.039 & 31.301 & 3.280 & 0.005 & 75.251 & 2.755 & 0.014 & 1.896 & 2.296 & 0.036 \\
\hline ANP & 0.364 & 0.725 & 0.479 & 0.130 & 0.472 & 0.643 & -5.228 & -1.445 & 0.168 & -2.358 & -0.228 & 0.823 & 0.213 & 0.680 & 0.506 \\
\hline BNP & -0.051 & -0.168 & 0.869 & 0.000 & -0.002 & 0.999 & -1.524 & -0.700 & 0.494 & 0.761 & 0.122 & 0.904 & -0.031 & -0.164 & 0.872 \\
\hline
\end{tabular}

SBP, systolic blood pressure; DBP, diastolic blood pressure; E, epinephrine; NE, norepinephrine; VMA, vanillylmandelic acid; AMH, adrenal medullary hyperplasia; ADM, adrenomedullin; ANP, atrial natriuretic peptide; BNP, brain natriuretic peptide.

of arterial systolic and diastolic blood pressure (SBP and $\mathrm{DBP})$ were significantly higher in the $\mathrm{EH}$ and $\mathrm{AMH}$ patients compared with the controls $(\mathrm{P}<0.05)$. No differences in SBP and DBP were detected between $\mathrm{EH}$ and $\mathrm{AMH}$ patients. Similar changes were observed in blood urea nitrogen (BUN), serum creatinine (Scr), and glomerular filtration rates (GFR) among the three groups.

As expected, the AMH patients had significantly higher mean values of serum $\mathrm{E}$, serum $\mathrm{NE}$ and urine VMA $(\mathrm{P}<0.05)$. The mean values of left ventricular ejection fraction (LVEF) were significantly reduced in the $\mathrm{EH}$ and $\mathrm{AMH}$ patients compared with the controls, whereas the mean values of left ventricualr mass index (LVMI) were significantly higher in the $\mathrm{EH}$ and $\mathrm{AMH}$ patients than in the controls $(\mathrm{P}<0.05)$. A significant difference in LVEF and LVMI was also detected between the controls and $\mathrm{EH}$ patients $(\mathrm{P}<0.05)$.
Plasma concentrations of ADM, ANP and BNP. The plasma concentrations of ADM, ANP and BNP in the study groups are showed in Fig. 1. The mean concentration of ADM was significantly higher in the AMH group $(9.61 \pm 2.78 \mathrm{pmol} / \mathrm{l})$ compared with the $\mathrm{EH}(6.51 \pm 2.00 \mathrm{pmol} / \mathrm{l})$ and control $(3.35 \pm 1.45 \mathrm{pmol} / \mathrm{l})$ groups $(\mathrm{P}<0.05)$. A significant difference in the mean ADM concentration was detected between the EH patients and controls. The mean values of ANP in the controls, EH patients and AMH patients were $2.95 \pm 1.32,12.54 \pm 3.54$ and $19.09 \pm 5.83 \mathrm{pmol} / 1$, respectively, whereas the mean values of BNP in the three groups were $4.52 \pm 1.87,26.53 \pm 7.70$ and $36.29 \pm 10.89 \mathrm{pmol} / 1$, respectively. Similar changes were observed in the mean values of ANP and BNP among the three groups.

Concentrations of E, NE, ADM, ANP and BNP in the IVC and adrenal vein of AMH patients. As shown in Tables II and III, 

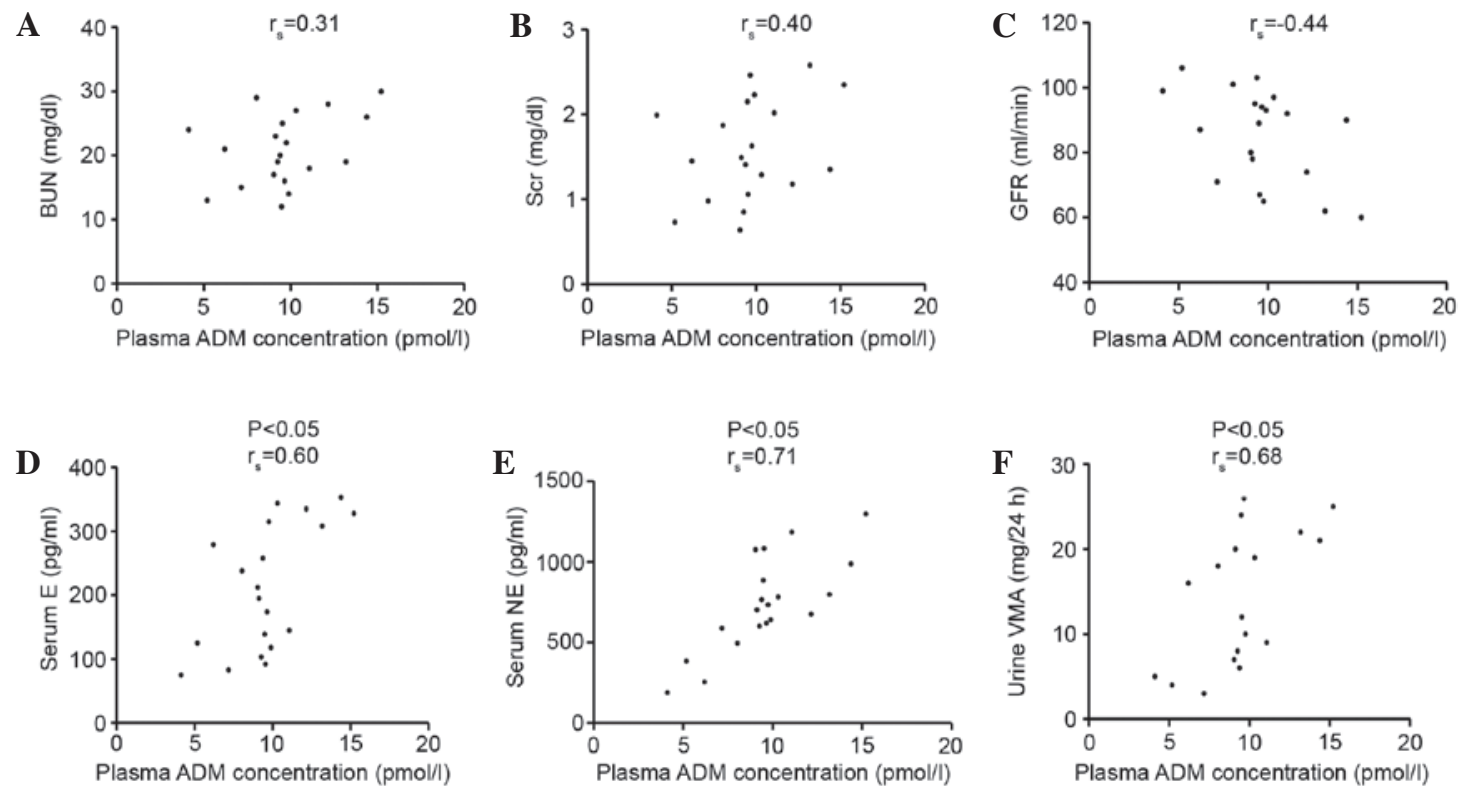

Figure 2. Association between plasma ADM concentration and values of (A) BUN, (B) Scr, (C) GFR, (D) serum E, (E) serum NE and (F) urine VMA in AMH group. The plasma ADM concentration was not associated with BUN, Scr and GFR, while it was correlated with serum E, serum NE and urine VMA $(\mathrm{P}<0.05)$. ADM, adrenomedullin; BUN, blood urea nitrogen; Scr, serum creatinine; GFR, glomerular filtration rate; E, epinephrine; NE, norepinephrine; VMA, vanillylmandelic acid.

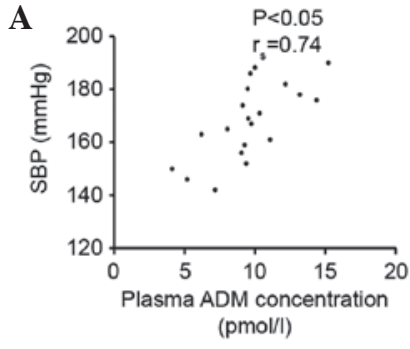

D

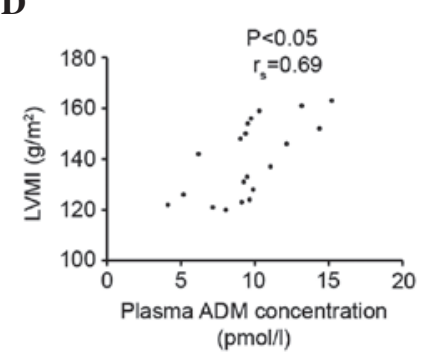

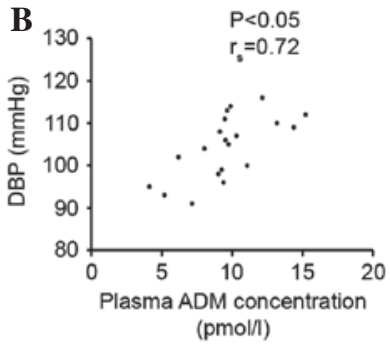

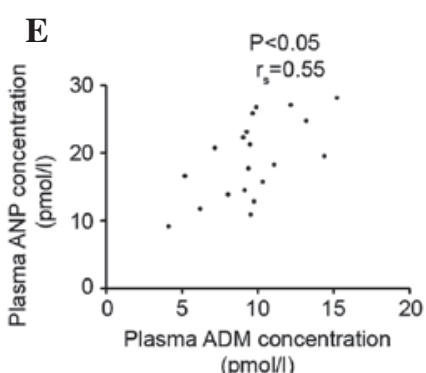

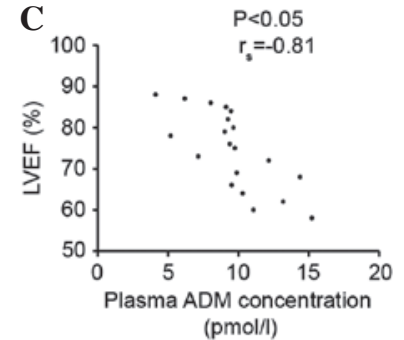

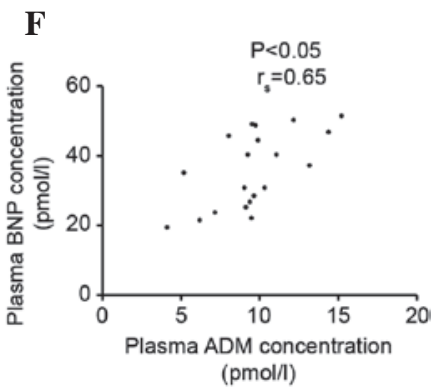

Figure 3. Association between plasma ADM concentration to values of (A) SBP, (B) DBP, (C) LVEF, (D) LVMI, (E) ANP and (F) BNP in AMH group. The plasma ADM concentration was not only associated with SBP, DBP, LVEF and LVMI, but also correlated with plasma levels of ANP and BNP (P<0.05). ADM, adrenomedullin; SBP, systolic blood pressure; DBP, diastolic blood pressure; LVEF, left ventricular ejection fraction; LVMI, left ventricular mass index; ANP, atrial natriuretic peptide; BNP, brain natriuretic peptide.

the concentrations of ADM, ANP and BNP in the contralateral adrenal vein, along with the concentrations of $\mathrm{E}$ and $\mathrm{NE}$, were significantly higher than in the infra- and supraadrenal IVCs. Moreover, there were further increases in the AMH adrenal vein than in the contralateral adrenal vein. There were no significant differences in the concentrations of the three peptides between infra- and supraadrenal IVCs.

Association between $S B P, D B P$, serum E, serum NE or urine $V M A$ and $A D M, A N P$ and BNP in patients with AMH. As shown in Table IV, ADM was the most important peptide associated with catecholamines or blood pressure in the AMH patients. Stepwise multiple regression analysis of independent parameters (ADM, ANP and BNP) associated with the values of SBP, DBP, serum E, serum NE or urine VMA was also conducted.

Association between plasma ADM concentration and values of BUN, Scr, GFR, serum E, serum NE and urine VMA. Fig. 2 shows the association between plasma ADM concentration and BUN, Scr, GFR, serum E, serum NE and urine VMA in the AMH group. The plasma ADM concentration was not 
Table V. Mean concentrations of ADM, ANP and BNP in AMH patients with or without renal dysfunction.

\begin{tabular}{lcccc}
\hline Characteristic & No. & ADM $(\mathrm{pmol} / \mathrm{l})$ & ANP $(\mathrm{pmol} / \mathrm{l})$ & $\mathrm{BNP}(\mathrm{pmol} / \mathrm{l})$ \\
\hline AMH patients & & & & \\
Scr $\geq 1.5 \mathrm{mg} / \mathrm{dl}$ & 9 & $10.04 \pm 3.11^{\mathrm{a}}$ & $20.64 \pm 6.13^{\mathrm{a}}$ & $39.53 \pm 10.93^{\mathrm{a}}$ \\
$\mathrm{Scr}<1.5 \mathrm{mg} / \mathrm{dl}$ & 11 & $9.25 \pm 2.88^{\mathrm{a}}$ & $17.82 \pm 5.54^{\mathrm{a}}$ & $33.64 \pm 10.62^{\mathrm{a}}$ \\
GFR $\leq 80 \mathrm{ml} / \mathrm{min}$ & 8 & $10.31 \pm 2.59^{\mathrm{a}}$ & $19.69 \pm 5.59^{\mathrm{a}}$ & $36.97 \pm 10.35^{\mathrm{a}}$ \\
GFR $>80 \mathrm{ml} / \mathrm{min}$ & 12 & $9.14 \pm 2.91^{\mathrm{a}}$ & $2.95 \pm 1.32$ & $35.84 \pm 11.67^{\mathrm{a}}$ \\
Control subjects & 40 & $3.35 \pm 1.45$ & $4.52 \pm 1.87$ \\
\hline
\end{tabular}

AMH, adrenal medullary hyperplasia; ADM, adrenomedullin; ANP, atrial natriuretic peptide; BNP, brain natriuretic peptide; Scr, serum creatinine; GFR, glomerular filtration rate. ${ }^{\mathrm{a}} \mathrm{P}<0.05$ vs. control subjects.

Table VI. Mean concentrations of ADM, ANP and BNP in EH patients with or without renal dysfunction.

\begin{tabular}{lcccc}
\hline Characteristic & No. & ADM $(\mathrm{pmol} / \mathrm{l})$ & ANP $(\mathrm{pmol} / \mathrm{l})$ & BNP $(\mathrm{pmol} / \mathrm{l})$ \\
\hline EH patients & & & & \\
Scr $\geq 1.5 \mathrm{mg} / \mathrm{dl}$ & 11 & $7.03 \pm 2.12^{\mathrm{a}}$ & $13.63 \pm 3.63^{\mathrm{a}}$ & $27.53 \pm 8.29^{\mathrm{a}}$ \\
$\mathrm{Scr}<1.5 \mathrm{mg} / \mathrm{dl}$ & 24 & $6.27 \pm 1.94^{\mathrm{a}}$ & $12.04 \pm 3.46^{\mathrm{a}}$ & $26.08 \pm 7.56^{\mathrm{a}}$ \\
GFR $\leq 80 \mathrm{ml} / \mathrm{min}$ & 9 & $7.08 \pm 2.31^{\mathrm{a}}$ & $13.51 \pm 3.86^{\mathrm{a}}$ & $28.11 \pm 8.62^{\mathrm{a}}$ \\
GFR $>80 \mathrm{ml} / \mathrm{min}$ & 26 & $6.31 \pm 1.90^{\mathrm{a}}$ & $2.21 \pm 3.44^{\mathrm{a}}$ & $25.99 \pm 7.46^{\mathrm{a}}$ \\
Control subjects & 40 & $3.35 \pm 1.45$ & $2.95 \pm 1.32$ & $4.52 \pm 1.87$ \\
\hline
\end{tabular}

EH, essential hypertension; ADM, adrenomedullin; ANP, atrial natriuretic peptide; BNP, brain natriuretic peptide; Scr, serum creatinine; GFR, glomerular filtration rate. ${ }^{\mathrm{a}} \mathrm{P}<0.05$ vs. control subjects.

Table VII. Parameters of AMH patients $(\mathrm{n}=20)$ at diagnosis and following drug administration and surgery.

\begin{tabular}{lccc}
\hline Parameter & At diagnosis & After drugs & After surgery \\
\hline Systolic BP (mmHg) & $168 \pm 15$ & $130 \pm 6$ & $127 \pm 5^{\text {a,b }}$ \\
Diastolic BP (mmHg) & $104 \pm 7$ & $80 \pm 5$ & $78 \pm 4^{\text {a,b }}$ \\
BUN (mg/dl) & $21 \pm 5$ & $20 \pm 3$ & $22 \pm 5$ \\
Scr (mg/dl) & $1.6 \pm 0.6$ & $1.4 \pm 0.3$ & $1.7 \pm 0.6$ \\
GFR (ml/min) & $85 \pm 14$ & $90 \pm 17$ & $86 \pm 15$ \\
Serum E (pg/ml) & $211 \pm 98$ & $213 \pm 99$ & $88 \pm 15^{\mathrm{a}, \mathrm{b}}$ \\
Serum NE (pg/ml) & $738 \pm 292$ & $754 \pm 303$ & $306 \pm 114^{\mathrm{a}, \mathrm{b}}$ \\
Urine VMA $(\mathrm{mg} / 24 \mathrm{~h})$ & $16 \pm 9$ & $17 \pm 8$ & $4 \pm 1^{\mathrm{a}, \mathrm{b}}$ \\
LVEF $(\%)$ & $75 \pm 7$ & $76 \pm 6$ & $81 \pm 4^{\mathrm{a}, \mathrm{b}}$ \\
LVMI $\left(\mathrm{g} / \mathrm{m}^{2}\right)$ & $140 \pm 15$ & $135 \pm 10$ & $118 \pm 8^{\mathrm{a}, \mathrm{b}}$ \\
\hline
\end{tabular}

AMH, adrenal medullary hyperplasia; BP, blood pressure; BUN, blood urea nitrogen; Scr, serum creatinine; GFR, glomerular filtration rate; E, epinephrine; NE, norepinephrine; VMA, vanillylmandelic acid; LVEF, left ventricular ejection fraction; LVMI, left ventricular mass index. ${ }^{\mathrm{a}} \mathrm{P}<0.05$ vs. subjects at diagnosis; ${ }^{\mathrm{b}} \mathrm{P}<0.05$ vs. subjects after drugs.

associated with BUN, Scr and GFR, while it was correlated with serum $\mathrm{E}$, serum NE and urine VMA $(\mathrm{P}<0.05)$.

Association between plasma ADM concentration and SBP, $D B P, L V E F, L V M I, A N P$ and BNP. Fig. 3 shows the association between plasma ADM concentration and SBP, DBP, LVEF, LVMI, ANP and BNP in the AMH group. The plasma ADM concentration was significantly associated with SBP,
DBP, LVEF and LVMI, and plasma levels of ANP and BNP $(\mathrm{P}<0.05)$.

Concentrations of ADM, ANP and BNP in AMH patients with or without renal dysfunction. Mean plasma concentrations of ADM, ANP and BNP in the AMH group with or without renal dysfunction are listed in Table V. No significant differences were detected between the patients with (Scr $\geq 1.5 \mathrm{mg} / \mathrm{dl}$ 


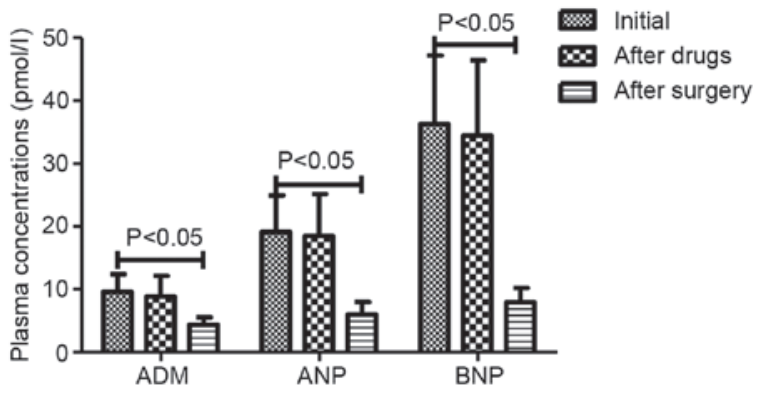

Figure 4. Plasma ADM, ANP and BNP concentrations initially, 4 weeks after effective antihypertensive therapy and 2 weeks after surgery in $\mathrm{AMH}$ group. The plasma concentrations of ADM, ANP and BNP were not significantly changed after drug treatment but significantly reduced after surgery $(\mathrm{P}<0.05)$. ADM, adrenomedullin; ANP, atrial natriuretic peptide; BNP, brain natriuretic peptide

or GFR $\leq 80 \mathrm{ml} / \mathrm{min}$ ) and without $(\mathrm{Scr}<1.5 \mathrm{mg} / \mathrm{dl}$ or GFR $>80 \mathrm{ml} / \mathrm{min}$ ) renal dysfunction, although the values of ADM, ANP and BNP in the patients with or without renal dysfunction were higher compared with the controls $(\mathrm{P}<0.05)$.

Concentrations of ADM, ANP and BNP in EH patients with or without renal dysfunction. Table VI shows the plasma concentrations of ADM, ANP and BNP in EH patients with or without renal dysfunction. There were no significant differences between patients with renal dysfunction $(\mathrm{Scr} \geq 1.5 \mathrm{mg} / \mathrm{dl}$ or GFR $\leq 80 \mathrm{ml} / \mathrm{min}$ ) and subjects without renal dysfunction (Scr $<1.5 \mathrm{mg} / \mathrm{dl}$ or GFR $>80 \mathrm{ml} / \mathrm{min}$ ), although the values of ADM, ANP and BNP in patients with or without renal dysfunction were higher compared with the controls $(\mathrm{P}<0.05)$.

Parameters of AMH patients at diagnosis and following drug administration and surgery. Table VII shows the clinical parameters of AMH patients at diagnosis, after drugs and after surgery, respectively. The SBP and DBP were normal following drug administration and surgery $(\mathrm{P}<0.05)$. The BUN, Scr and GFR were not significantly different before and after treatment. The plasma E, plasma NE, urine VMA, LVEF and LVMI were not significantly changed after drugs but were normal after surgery $(\mathrm{P}<0.05)$.

Plasma ADM, ANP, and BNP concentrations at diagnosis and following drug administration and surgery. The plasma ADM, ANP, and BNP concentrations initially, 4 week after effective antihypertensive therapy and 2 weeks after surgery in AMH group are presented in Fig. 4. Plasma concentration of ADM was not significantly changed after drug treatment $(9.61 \pm 2.78$ to $8.85 \pm 3.29 \mathrm{pmol} / \mathrm{l})$, but significantly reduced after surgery $(9.61 \pm 2.78$ to $4.34 \pm 1.23 \mathrm{pmol} / \mathrm{l} ; \mathrm{P}<0.05)$. The plasma ANP and BNP levels similarly declined after drug treatment $(19.09 \pm 5.83$ to $18.48 \pm 6.67$ and $36.29 \pm 10.89$ to $34.42 \pm 12.02 \mathrm{pmol} / 1$, respectively) and after surgery $(19.09 \pm 5.83$ to $5.99 \pm 2.00$ and $36.29 \pm 10.89$ to $7.93 \pm 2.28 \mathrm{pmol} / 1$, respectively; $\mathrm{P}<0.05)$.

The plasma concentrations of ADM, ANP and BNP were analyzed initially and at 4 weeks after effective antihypertensive therapy in the EH patients when the BP was normal. The concentrations of ADM, ANP, and BNP significantly decreased after drug treatment $(6.51 \pm 2.00$ to $4.05 \pm 1.43$,
$12.54 \pm 3.54$ to $7.35 \pm 2.41,26.53 \pm 7.70$ to $18.32 \pm 4.65 \mathrm{pmol} / 1$ respectively; $\mathrm{P}<0.05)$.

\section{Discussion}

ADM is involved in the regulation of heart and kidney function, and inhibition of vascular smooth muscle cell proliferation and migration and cardiac remodelling $(19,20)$. It has been demonstrated that this peptide is present in a variety of organs and cells in addition to human plasma, and exerts a wide range of physiological effects, including cardiovascular protection, neovascularization and apoptosis suppression (21). Sporadic AMH is characterized by excessive catecholamine excretion arising from chromaffin cells of the adrenal medulla or extra-adrenal location, and may result in secondary hypertension and high oxygen consumption (22). Furthermore, in addition to catecholamines, chromaffin cells produce and secrete elevated quantities of trophic peptides which are normally released in a regulated manner by the normal adrenal medulla, and one of these peptides, ADM, is particularly high (23). ANP and BNP are similar to ADM in cardiovascular effects, including natriuresis, diuresis, hypotensive action and anti-hypertrophic action, thereby reducing fluid volume and increasing oxygen transport $(24,25)$. Previous studies have shown that plasma levels of ADM, ANP and BNP were elevated in patients with essential hypertension $(26,27)$.

In the present study, the EH and AMH patients had significant higher mean BUN and Scr values and lower mean GFR values compared with the controls. Thus, essential or secondary hypertension resulting from AMH may lead to renal dysfunction. These results are compatible with our previous report (unpublished data). In addition, the BUN, Scr and GFR values in AMH patients were not changed following drug administration and surgical treatment. It may have been the case that certain long-standing or elderly patients had slightly irreversible renal impairment. The EH and AMH patients had significantly lower LVEF and higher LVMI compared with the controls. In addition, there was a significant difference between EH patients and controls. The LVEF and LVMI significantly improved after drugs in EH patients (unpublished data). However, the LVEF and LVMI remained unchanged following drug treatment, but significantly improved along with serum E, serum NE and urine VMA in AMH patients. Thus, the changes of LVEF and LVMI may be due to catecholamine cardiomyopathy, resulting from catecholamine hypersecretion which was confirmed by the association between plasma ADM concentration to LVEF and LVMI.

Another notable result was that the plasma concentrations of ADM, ANP and BNP were significantly higher in AMH patients compared with EH patients and controls. Furthermore, significant differences in mean values of the three peptides were detected in EH patients and controls. Therefore, it may be inferred that ADM participates alongside ANP and BNP in the compensatory and protective mechanisms counteracting further elevation of blood pressure in the cardiovascular system, due to their similar physiological functions. This can be confirmed by the association between plasma ADM concentrations and SBP and DBP. Furthermore, ADM was identified as the most important peptide in AMH patients, 
which was confirmed by stepwise multiple regression analysis of independent parameters associated with SBP, DBP, serum E, serum NE or urine VMA. Furthermore, the elevated levels of the three peptides significantly decreased following drug treatment in EH patients (unpublished data), whereas the elevated levels were only significantly reduced after laparoscopic adrenalectomy in AMH patients. A potential explanation is that the elevated concentrations of the three peptides in the $\mathrm{AMH}$ patients were associated with catecholamine hypersecretion. Indeed, the concentrations of the three peptides in the contralateral adrenal vein, along with the concentrations of $\mathrm{E}$ and NE, were significantly higher compared with those of infra- and supraadrenal IVCs. The significant increases were observed in the concentrations of the three peptides in the AMH adrenal vein than in the contralateral adrenal vein. These results appear to be compatible with studies by Cotesta et al (15) and Lee et al (28), though the study subjects were patients with pheochromocytoma and primary aldosteronism, respectively. However, the plasma ADM concentration was associated with serum E, serum NE and urine VMA, in addition to the plasma concentrations of ANP and BNP. On the basis of these results, it may be inferred that ADM, ANP and BNP can be released from adrenal medulla along with the catecholamine secretion and the quantity was higher when the adrenal medulla was hyperplastic. Therefore, ADM, ANP and BNP may be important in the regulation of adrenal medulla functions. The specific molecular regulating pathways for this are unclear at present and further studies will be necessary to clarify them.

In the present study, there were no significant differences in plasma concentrations of ADM, ANP and BNP between patients with and without renal dysfunction in $\mathrm{EH}$ and $\mathrm{AMH}$ patients. This was confirmed by the absence of association between plasma ADM concentration and BUN, Scr and GFR. Therefore, elevated levels of ADM, ANP and BNP were not associated with renal function.

As aforementioned, a number of investigations showed increased plasma ADM, ANP and BNP levels in patients with $\mathrm{EH}$, or primary aldosteronism or pheochromocytoma $(14,26,27,29-31)$; however, this is the first study to assess plasma ADM, ANP and BNP levels in patients with AMH.

Collectively, the present results indicate that ADM may participate, along with ANP and BNP, in the mechanisms acting against further elevation of blood pressure. They may be good predictors of catecholamine hypersecretion and involved in the regulation of adrenal medulla in $\mathrm{AMH}$ patients. However, this is a retrospective observation based on a small number of cases due to the low incidence of $\mathrm{AMH}$, and further studies are necessary to identify the specific pathophysiological significance of ADM, ANP and BNP in AMH and the exact pharmacokinetics underlying their activity in $\mathrm{AMH}$ patients.

\section{Acknowledgements}

This study was approved by the Ethics Committee of Renmin Hospital Wuhan University. The authors thank the Department of Urology in Renmin Hospital of Wuhan University. This study was supported by grants from the National Science Fund Project of China (grant no. 81501921) and the Doctor
Research Fund Project of Wuhan University of China (grant no. 2012302020203).

\section{References}

1. Kitamura K, Kangawa K, Kawamoto M, Ichiki Y, Nakamura S, Matsuo H and Eto T: Adrenomedullin: A novel hypotensive peptide isolated from human pheochromocy toma. 1993. Biochem Biophys Res Commun 425, 548-555, 2012.

2. Cheung BM, Li CY and Wong LY: Adrenomedullin: Its role in the cardiovascular system. Semin Vasc Med 4: 129-134, 2004.

3. Minamino N: Adrenomedullin, its distribution and regulation of production. Nihon Rinsho 62 (Suppl 9), S193-S197, 2004.

4. Cheung BM and Tang F: Adrenomedullin: Exciting new horizons. Recent Pat Endocr Metab Immune Drug Discov 6, 4-17, 2012.

5. Wong HK, Cheung TT and Cheung BM: Adrenomedullin and cardiovascular diseases. JRSM Cardiovasc Dis 1: pii: cvd.2012.012003, 2012.

6. Li Y, Jiang C, Wang X, Zhang Y, Shibahara S and Takahashi K: Adrenomedullin is a novel adipokine: Adrenomedullin in adipocytes and adipose tissues. Peptides 28, 1129-1143, 2007.

7. Nishikimi T, Kuwahara K, Nakagawa Y, Kangawa K and Nakao K: Adrenomedullin in cardiovascular disease: A useful biomarker, its pathological roles and therapeutic application. Curr Protein Pept Sci 14, 256-267, 2013.

8. Arjamaa O: Physiology of natriuretic peptides: The volume overload hypothesis revisited. World J Cardiol 6: 4-7, 2014.

9. Chowdhury P, Kehl D, Choudhary R and Maisel A: The use of biomarkers in the patient with heart failure. Curr Cardiol Rep 15, 372, 2013.

10. Clerico A, Giannoni A, Vittorini S and Passino C: Thirty years of the heart as an endocrine organ: Physiological role and clinical utility of cardiac natriuretic hormones. Am J Physiol Heart Circ Physiol 301, H12-H20, 2011.

11. Federico C: Natriuretic peptide system and cardiovascular disease. Heart Views 11: 10-15, 2010.

12. Kuhn M: Endothelial actions of atrial and b-type natriuretic peptides. Br J Pharmacol 166: 522-531, 2012.

13. Lu WW and Qi YF: Cardiovascular effects and pathophysiological significance of adrenomedullin family peptides. Sheng Li Ke Xue Jin Zhan 44: 177-182, 2013 (In Chinese).

14. Whitworth JA; World Health Organization, International Society of Hypertension Writing Group: 2003 World Health Organization (WHO)/International Society of Hypertension (ISH) statement on management of hypertension. J Hypertens 21: 1983-1992, 2003.

15. Cotesta D, Caliumi C, Alò P, Petramala L, Reale MG Masciangelo R, Signore A, Cianci R, D'Erasmo E and Letizia C: High plasma levels of human chromogranin a and adrenomedullin in patients with pheochromocytoma. Tumori 91: 53-58, 2005.

16. Ohta H, Tsuji T, Asai S, Tanizaki S, Sasakura K, Teraoka H, Kitamura $\mathrm{K}$ and Kangawa $\mathrm{K}$ : A simple immunoradiometric assay for measuring the entire molecules of adrenomedullin in human plasma. Clin Chim Acta 287, 131-143, 1999.

17. Ohta H, Tsuji T, Asai S, Sasakura K, Teraoka H, Kitamura K and Kangawa K: One-step direct assay for mature-type adrenomedullin with monoclonal antibodies. Clin Chem 45: 244-251, 1999.

18. Yasue H, Yoshimura M, Sumida H, Kikuta K, Kugiyama K, Jougasaki M, Ogawa H, Okumura K, Mukoyama M and Nakao K: Localization and mechanism of secretion of $b$-type natriuretic peptide in comparison with those of A-type natriuretic peptide in normal subjects and patients with heart failure. Circulation 90: 195-203, 1994.

19. Beltowski J and Jamroz A: Adrenomedullin-what do we know 10 years since its discovery? Pol J Pharmacol 56: 5-27, 2004.

20. Kato J, Kitamura K and Eto T: Plasma adrenomedullin level and development of hypertension. J Hum Hypertens 20: 566-570, 2006.

21. Garcia MA, Martín-Santamaría S, de Pascual-Teresa B Ramos A, Julián M and Martínez A: Adrenomedullin: A new and promising target for drug discovery. Expert Opin Ther Targets 10: 303-317, 2006.

22. Marín MR, Arenas MF, Valverde FM, Garaulet ET, Maderuelo MM, Avilés AM, Quirante FP and Blázquez AA: Laparoscopic adrenalectomy for nonfamilial adrenal medullary hyperplasia. JSLS 17: 433-439, 2013. 
23. Thouennon E, Pierre A, Yon L and Anouar Y: Expression of trophic peptides and their receptors in chromaffin cells and pheochromocytoma. Cell Mol Neurobiol 30: 1383-1389, 2010.

24. Sergeeva IA and Christoffels VM: Regulation of expression of atrial and brain natriuretic peptide, biomarkers for heart development and disease. Biochim Biophys Acta 1832: 2403-2413, 2013.

25. Saito Y: Roles of atrial natriuretic peptide and its therapeutic use. J Cardiol 56: 262-270, 2010.

26. Nishikimi T: Adrenomedullin in essential hypertension. Nihon Rinsho 62 (Suppl 9): S260-S263, 2004 (In Japanese).

27. Soualmia H, Ayadi I, Omar S, Feki M, Drissa H, Mebazaa A and Kaabachi N: Atrial natriuretic peptide and brain natriuretic peptide release in human essential hypertension. Clin Lab 55: 120-127, 2009.
28. Lee YJ, Lin SR, Shin SJ, Lai YH, Lin YT and Tsai JH: Brain natriuretic peptide is synthesized in the human adrenal medulla and its messenger ribonucleic acid expression along with that of atrial natriuretic peptide are enhanced in patients with primary aldosteronism. J Clin Endocrinol Metab 79: 1476-1482, 1994

29. Letizia C, De Toma G, Cerci S, Massa R, Coassin S, Subioli S, Scuro L and De Ciocchis A: Adrenomedullin levels are high in primary aldosteronism due to adenoma and decline after surgical cure. Blood Press 7: 19-23, 1998.

30. Kato J, Etoh T, Kitamura K and Eto T: Atrial and brain natriuretic peptides as markers of cardiac load and volume retention in primary aldosteronism. Am J Hypertens 18: 354-357, 2005.

31. Letizia C, De Toma G, Caliumi C, Cerci S, Massa R, Loria RD, Alo P, Marinoni EM, Diacinti D and D'Erasmo E: Plasma adrenomedullin concentrations in patients with adrenal pheochromocytoma. Horm Metab Res 33: 290-294, 2001. 